\title{
AKTIVITAS EKSTRAK BIJI TANAMAN MINDI MELIA AZEDARACH (L.) TERHADAP SPODOPTERA LITURA (F.) (LEPIDOPTERA: NOCTUIDAE)
}

\author{
Hamdani $^{1}$
}

\section{ABSTRACT}

Activity of Melia azedarach (L.) seed extract against armyworm Spodoptera litura (F.) (Lepidoptera: Noctuidae). This study was conducted to evaluate the effectivenes and biological activity of Melia azedarach L. (Meliaceae) seed extract against armyworm, Spodoptera litura F. The first instar larvae were fed extract-treated cotton leaves for 2 days, then were maintained on untreated leaves until the third instar stage. Records were kept in regard to the larvae mortality and developmental time of surviving larvae from first instar to third instar. The result showed that Melia azedarach L. seed extract at consentration of $50 \mathrm{~g}$ of seeds/l of water (5\%) exhibited moderate insecticidal activity against $S$. litura larvae (43.33 - 68.33\% mortality). Addition of detergen at $0.2 \%$ to extract did not increase insecticidal activity of the extract. However, boiling seed extract at consentration of $50 \mathrm{~g}$ of seeds/l of water (5\%) during 10 until 20 minutes increased insecticidal activity of extract (66.67 - 68.33\% mortality). Generally, M. azedarach seed extract treatment did not affect developmental time of $S$. litura larvae.

Key words : biological activity, extract, Melia azedarach, Spodoptera litura

\section{PENDAHULUAN}

Spodoptera litura ((F.)) (Lepidoptera: Noctuidae) merupakan hama yang penting pada tanaman pangan maupun pada tanaman perkebunan, karena larva hama ini bersifat polifag. Larva hama ini sering menyebabkan kerusakan daun pada tanaman kacang-kacangan, jagung, padi, bawang, slada, sawi, kapas, tembakau, dan tebu (Kalshoven, 1981).

Upaya pengendalian yang dilakukan umumnya menggunakan insektisida sintetik dengan frekuensi penyemprotan terjadwal 2 - 3 kali per minggu. Namun tindakan tersebut tidak mampu menurunkan populasi, karena larva S. litura tersebut pada siang hari bersembunyi di dalam tanah (Soekarna, 1984). Selain itu pengendalian hama tanaman dengan insektisida dapat menimbulkan dampak negatif, seperti resistensi dan resurjensi hama, terbunuhnya organisme bukan sasaran termasuk musuh alami, keracunan pada manusia dan ternak, kontaminasi oleh residu bahan beracun pada hasil panen, dan pencemaran lingkungan secara umum (Parrella \& Keil, 1984; Schmutterer, 1995).

Sehubungan dengan hal tersebut penelitian pemanfaatkan ekstrak tanaman untuk mengendalikan populasi dan serangan hama tanaman perlu dilakukan agar diperoleh/diketahui alternatif pengedalian hama yang lebih murah, aman terhadap lingkungan, dan dapat diterima oleh para petani. Dengan demikian ketergantungan petani dengan pestisida sintetik dapat dikurangi bahkan dihilangkan dan kerusakan lingkungan secara umum dapat dihindari, sehingga konsep pertanian ekologis atau pertanian berkelanjutan dapat diwujudkan.

Hingga saat ini telah diketahui terdapat tiga sumber insektisida alami yang penting dan memiliki prospek yang baik untuk dikembangkan, yaitu tumbuhan, mikroorganisme tanah, dan organisme laut. Jenis tumbuhan yang diketahui berpotensi sebagai sumber insektisida nabati yang potensial antara lain famili Meliaceae, Annonaceae, Piperaceae, Asteraceae, Zingiberaceae dan Leguminosae (Chiu, 1985; Koul et al., 1997; Prijono, 1998; Dadang, 1999).

Contoh tanaman Meliaceae yang potensial antara lain mimba (Azadirachta indica), mindi (Melia azedarach), suren (Toona sureni), culan (Aglaia odorata) (Chiu, 1985; Satasook et al., 1994; Ewete et al., 1996; Koul et al., 1997). Ekstrak beberapa bagian tanaman tersebut terbukti aktif sebagai insektisida, antifeedant, penghambat perkembangan, serta penghambat peneluran, namun yang paling aktif adalah ekstrak biji (Dadang, 1999; Prijono 1999).

Peningkatan konsentrasi senyawa aktif dalam ekstrak dengan pelarut air dapat dilakukan dengan dua cara, yaitu menambahkan sedikit deterjen yang berfungsi sebagai pengemulsi dan merebus campuran bahan ekstrak selama beberapa saat (Prijono, 1999).

Berdasarkan latar belakang tersebut di atas serta mempertimbangkan kemudahan mendapatkan tanaman mindi di sekitar lahan pertanian, utamanya di Lampung, maka penelitian keefektifan insektisida

\footnotetext{
${ }^{1}$ Dosen Politeknik Negeri Lampung, Jl. Soekarno - Hatta, Rajabasa Bandar Lampung, 35144
} 
nabati ekstrak biji tanaman mindi (M. azedarach) terhadap ulat pemakan daun Spodoptera litura (F.) ini dilakukan.

\section{METODE PENELITIAN}

\section{Tempat dan Waktu}

Penelitian dilaksanakan di Laboratorium Tanaman Politeknik Negeri Lampung, pada Agustus sampai Oktober 2003.

\section{Bahan Tanaman Sumber Ekstrak}

Bahan tanaman yang diekstrak adalah biji tanaman mindi ( $M$. azedarach) yang diperoleh dari Pekon Campang, Kecamatan Talangpadang, Kabupaten Tanggamus, Provinsi Lampung.

\section{Metode Ekstraksi}

Biji tanaman mindi yang sudah masak (jatuhan) dan masih segar dibersihkan dari kulit serta lendir dan dicuci hingga bersih. Kemudian, biji-biji tersebut dikeringanginkan dengan cara dihampar di atas lantai (tidak terkena sinar matahari langsung) dengan alas kertas koran selama 3 hari. Selanjutnya, biji digiling berulang kali (3-4 kali) dengan penggiling biji (Grader) hingga menjadi serbuk. Serbuk biji yang diperoleh dicampur air yang mengandung deterjen (Rinso) 0,2\% (w/v) dan tanpa deterjen dengan perbandingan $50 \mathrm{~g}$ serbuk/l air, kemudian campuran tersebut direbus selama 10; 20; 30 menit. Waktu perebusan dihitung sejak air mendidih. Setelah direbus dan didinginkan, ekstrak disaring dengan kain halus, kemudian ditambahkan air pada ampas hasil saringan hingga volume ekstrak yang diperoleh sama dengan volume air semula. Untuk memperoleh ekstrak tanpa direbus, campuran serbuk biji seperti tersebut di atas, setelah diaduk dan di diamkan beberapa saat, langsung disaring dengan kain halus. Ekstrak yang dihasilkan digunakan untuk pengujian.

\section{Serangga Uji}

Larva S. litura yang digunakan sebagai serangga uji merupakan hasil perbanyakan di Laboratorium Tanaman, Politeknik Pertanian Negeri Bandar Lampung. Imago dipelihara dalam kurungan plastik-kasa dengan bingkai kayu yang berukuran 40 $\mathrm{cm}$ x $40 \mathrm{~cm}$ x $40 \mathrm{~cm}$ dan diberi pakan berupa cairan madu $10 \%$ yang diserapkan pada gumpalan kapas. Di dalam kurungan diletakkan 2-3 helai daun kapas sebagai tempat imago meletakkan telur. Tangkai daun kapas dimasukkan ke dalam wadah film yang berisi air untuk mempertahankan turgor. Kelompok telur pada daun kapas dikumpulkan setiap hari dan ditempatkan dalam cawan petri berdiameter $15 \mathrm{~cm}$. Menjelang menetas, kelompok telur dipindahkan ke dalam wadah plastik berukuran $28 \mathrm{~cm}$ x $20 \mathrm{~cm}$ x $5 \mathrm{~cm}$ yang dilengkapi dengan jendela kasa. Larva yang baru keluar dari telur diberi makan daun kapas bebas pestisida. Larva instar pertama digunakan sebagai serangga uji. Larva yang tidak digunakan untuk pengujian dipelihara lebih lanjut dengan pakan daun kapas bebas pestisida. Menjelang berkepompong, larva dipindahkan ke wadah plastik lain yang berisi tanah steril. Kepompong yang terbentuk beserta kokonnya dimasukkan ke dalam kurungan plastikkasa seperti di atas hingga imago muncul dan menghasilkan telur untuk pemeliharaan selanjutnya.

\section{Metode Pengujian}

Perlakuan disusun mengikuti rancangan acak lengkap dengan 9 perlakuan dan 4 ulangan. Perlakuan yang diujikan adalah:

$$
\begin{aligned}
\mathrm{P}_{0}= & \text { air (kontrol). } \\
\mathrm{P}_{1}= & \text { ekstrak biji tanaman mindi }(50 \mathrm{~g} / \mathrm{l}) \text {, tanpa } \\
& \text { deterjen, tanpa direbus. } \\
\mathrm{P}_{2}= & \text { ekstrak biji tanaman mindi }(50 \mathrm{~g} / \mathrm{l}) \text {, tanpa } \\
& \text { deterjen, direbus } 10 \text { menit. } \\
\mathrm{P}_{3}= & \text { ekstrak biji tanaman mindi }(50 \mathrm{~g} / \mathrm{l}) \text {, tanpa } \\
& \text { deterjen, direbus } 20 \text { menit. } \\
\mathrm{P}_{4}= & \text { ekstrak biji tanaman mindi }(50 \mathrm{~g} / \mathrm{l}) \text {, tanpa } \\
& \text { deterjen, direbus } 30 \text { menit. } \\
\mathrm{P}_{5}= & \text { ekstrak biji tanaman mindi }(50 \mathrm{~g} / \mathrm{l})+\text { deterjen } \\
& 0,2 \% \text {, tanpa direbus. } \\
\mathrm{P}_{6}= & \text { ekstrak biji tanaman mindi }(50 \mathrm{~g} / \mathrm{l})+\text { deterjen } \\
& 0,2 \% \text {, direbus } 10 \text { menit. } \\
\mathrm{P}_{7}= & \text { ekstrak biji tanaman mindi }(50 \mathrm{~g} / \mathrm{l})+\text { deterjen } \\
& 0,2 \% \text {, direbus } 20 \text { menit. } \\
\mathrm{P}_{8}= & \text { ekstrak biji tanaman mindi }(50 \mathrm{~g} / \mathrm{l})+\text { deterjen } \\
& 0,2 \% \text {, direbus } 20 \text { menit. }
\end{aligned}
$$

Aktivitas ekstrak biji mindi terhadap S. litura diuji dengan metode pencelupan daun pakan seperti yang diuraikan oleh Prijono (1999). Potongan (cakram) daun kapas (diameter 3,5 cm) dicelupkan ke dalam ekstrak yang diuji sampai basah kemudian dikeringanginkan. Setelah kering, tiga helai potongan daun kapas diletakkan dalam cawan petri (diameter 9 $\mathrm{cm}$ ) yang dialasi kertas hisap, kemudian 15 ekor larva $S$. litura instar pertama dimasukkan ke dalamnya. Lama pemberian pakan berperlakuan adalah 48 jam, kemudian sisa pakan berperlakuan diganti dengan daun kapas tanpa perlakuan hingga akhir instar 
ketiga. Untuk menghindari saling makan sesama (kanibalisme) larva yang bertahan hidup dipelihara terpisah dalam cawan petri (satu ekor tiap cawan petri). Jumlah larva yang mati pada setiap perlakuan dicatat tiap hari hingga larva mencapai akhir instar ketiga. Angka-angka tersebut dijumlahkan untuk menghitung mortalitas untuk setiap perlakuan. Waktu ganti kulit larva yang bertahan hidup dan lama instar pertama sampai akhir instar ketiga juga dicatat untuk mengetahui pengaruh ekstrak terhadap lama pertumbuhan dan perkembangan larva.

\section{Analisis data}

Data mortalitas larva diolah dengan sidik ragam menggunakan program SAS (SAS Institute, 1990). Pembandingan nilai tengah antar perlakuan dilakukan dengan uji jarak berganda Duncan $(\alpha=$ 0,05 ). Untuk larva yang masih bertahan hidup, lama perkembangan larva dari instar pertama sampai akhir instar ketiga pada setiap perlakuan dibandingkan berdasarkan nilai rata-rata \pm simpangan bakunya.

\section{HASIL DAN PEMBAHASAN}

\section{Pengaruh ekstrak biji tanaman mindi terhadap mortalitas larva S. litura}

Pengaruh ekstrak biji tanaman mindi $M$. azedarach terhadap mortalitas larva ulat pemakan daun S. litura disajikan pada Gambar 1. Semua perlakuan ekstrak biji tanaman mindi yang diuji mengakibatkan mortalitas larva yang berbeda sangat nyata terhadap kontrol. Dengan demikian ekstrak biji tanaman mindi memiliki aktivitas insektisida terhadap larva S. litura.

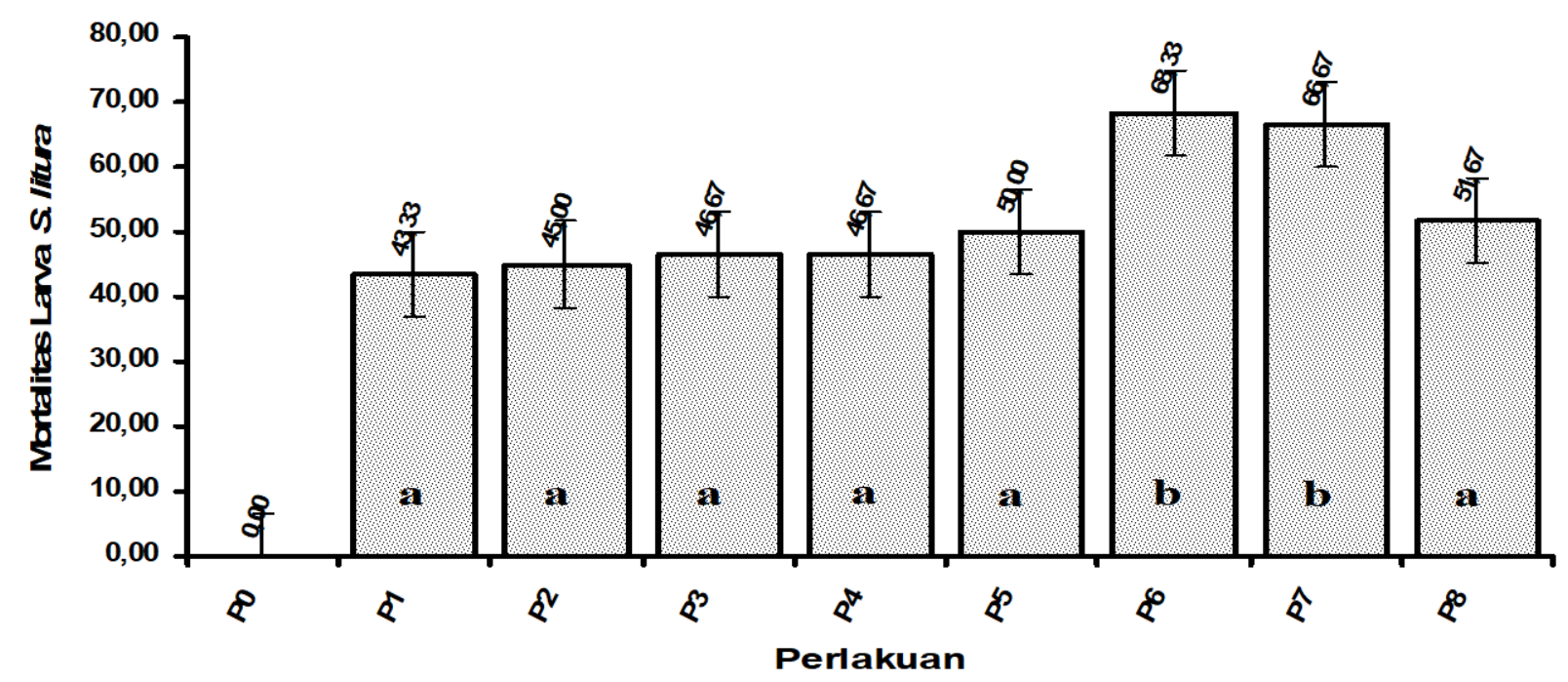

Gambar 1. Mortalitas larva S. litura akibat pemberian ekstrak biji tanaman mindi (M. azedarach) (Kotak pada grafik yang berhuruf sama tidak berbeda nyata Duncan, $\alpha=0,05), \mathrm{P}_{0}=$ air (Kontrol), $\mathrm{P}_{1}=$ ekstrak biji tanaman mindi (50 g/l), tanpa deterjen, tanpa direbus, $\mathrm{P}_{2}=$ ekstrak biji tanaman mindi (50 g/l), tanpa deterjen, direbus 10 menit, $\mathrm{P}_{3}=$ ekstrak biji tanaman mindi (50 g/l), tanpa deterjen, direbus 20 menit, $\mathrm{P}_{4}=$ ekstrak biji tanaman mindi (50 g/l), tanpa deterjen, direbus 30 menit, $\mathrm{P}_{5}=$ ekstrak biji tanaman mindi $(50 \mathrm{~g} / \mathrm{l})+$ deterjen $0,2 \%$, tanpa direbus, $\mathrm{P}_{6}=$ ekstrak biji tanaman mindi $(50 \mathrm{~g} / \mathrm{l})+$ deterjen $0,2 \%$, direbus 10 menit, $\mathrm{P}_{7}=$ ekstrak biji tanaman mindi $(50 \mathrm{~g} / \mathrm{l})+$ deterjen $0,2 \%$, direbus 20 menit, $\mathrm{P}_{8}=$ ekstrak biji tanaman mindi $(50 \mathrm{~g} / \mathrm{l})+$ deterjen $0,2 \%$, direbus 30 menit. 
Tabel 1. Lama perkembangan larva S. litura akibat pemberian ekstrak biji tanaman mindi (M. azedarach)

\begin{tabular}{|c|c|c|}
\hline Perlakuan & $\mathrm{N}$ & $\begin{array}{c}\text { lama perkembangan } \\
\text { larva instar I - III } \pm \text { SD } \\
\text { (hari) }\end{array}$ \\
\hline Air (Kontrol) & 60 & $10,12 \pm 0,22$ \\
\hline ekstrak biji tanaman mindi (50 g/l), tanpa deterjen, tanpa direbus & 34 & $10,26 \pm 0,37$ \\
\hline $\begin{array}{l}\text { ekstrak biji tanaman mindi ( } 50 \mathrm{~g} / \mathrm{l} \text { ), tanpa deterjen, direbus } 10 \\
\text { menit }\end{array}$ & 33 & $10,29 \pm 0,42$ \\
\hline $\begin{array}{l}\text { ekstrak biji tanaman mindi (50 g/l), tanpa deterjen, direbus } 20 \\
\text { menit }\end{array}$ & 32 & $10,20 \pm 0,33$ \\
\hline $\begin{array}{l}\text { ekstrak biji tanaman mindi (50 g/l), tanpa deterjen, direbus } 30 \\
\text { menit }\end{array}$ & 31 & $10,32 \pm 0,35$ \\
\hline ekstrak biji tanaman mindi (50 g/l) + deterjen $0,2 \%$, tanpa direbus & 30 & $10,27 \pm 0,31$ \\
\hline $\begin{array}{l}\text { ekstrak biji tanaman mindi }(50 \mathrm{~g} / \mathrm{l})+\text { deterjen } 0,2 \% \text {, direbus } 10 \\
\text { menit }\end{array}$ & 19 & $10,34 \pm 0,50$ \\
\hline $\begin{array}{l}\text { ekstrak biji tanaman mindi }(50 \mathrm{~g} / \mathrm{l})+\text { deterjen } 0,2 \% \text {, direbus } 20 \\
\text { menit }\end{array}$ & 20 & $10,28 \pm 0,34$ \\
\hline $\begin{array}{l}\text { ekstrak biji tanaman mindi }(50 \mathrm{~g} / \mathrm{l})+\text { deterjen } 0,2 \% \text {, direbus } 30 \\
\text { menit }\end{array}$ & 29 & $10,31 \pm 0,31$ \\
\hline
\end{tabular}

Keterangan:

SD : standar deviasi

$\mathrm{N}$ : Jumlah larva yang bertahan hidup sampai akhir instar III setelah diberi perlakuan

Ekstrak biji tanaman mindi dengan konsentrasi $50 \mathrm{~g}$ serbuk/l air dan mengandung deterjen $0,2 \%$ yang direbus selama 10 menit dan 20 menit menyebabkan mortalitas larva cukup tinggi, yaitu sebesar 68,33\% dan 66,67\%. Antara kedua nilai mortalitas larva $S$ litura tersebut tidak berbeda nyata, namun berbeda sangat nyata terhadap nilai mortalitas larva yang disebabkan oleh perlakuan lainnya.

Berdasarkan data mortalitas tersebut di atas, ternyata merebus ekstrak biji tanaman mindi $50 \mathrm{~g}$ serbuk/l air selama 10 sampai 20 menit dapat meningkatkan keefektifannya terhadap larva S. litura. Diduga hal ini terjadi karena bahan aktif pada ekstrak tersebut meningkat sehubungan dengan adanya pemanasan selama waktu tersebut. Menurut Prijono (1999) merebus atau mendidihkan bahan ekstrak selama waktu tertentu dapat meningkatkan bahan aktif yang terlarut dalam ekstrak yang diperoleh. Tetapi, penambahan waktu perebusan ekstrak sampai 30 menit ternyata menurunkan kefektifannya, nilai mortalitas larva akibat perlakuan ini hanya mencapai 51,67\%. Diperkirakan perebusan selama waktu tersebut dapat menyebabkan sebahagian besar bahan aktif ekstrak terurai (terdegradasi) menjadi tidak aktif dan atau menguap sehingga kadar bahan aktif yang diperoleh semakin rendah, akibatnya aktivitas ekstrak yang dihasilkan menjadi lebih lemah. Dugaan ini didekati dari hasil analisis bahwa, mortalitas larva pada ekstrak $50 \mathrm{~g}$ serbuk/l air yang mengandung deterjen $0,2 \%$ dan direbus selama 30 menit tidak berbeda nyata dengan mortalitas yang diakibatkan oleh ekstrak dengan konsentrasi dan kandungan deterjen yang sama tanpa perebusan.

Ekstrak biji tanaman mindi dengan konsentrasi $50 \mathrm{~g}$ serbuk/l air yang mengandung deterjen $0,2 \%$, tanpa direbus dan direbus selama 30 menit menyebabkan mortalitas larva S. litura sebesar $50 \%$ dan $51,67 \%$ dan tidak berbeda nyata antara keduanya. Kedua nilai mortalitas tersebut juga tidak berbeda nyata terhadap nilai mortalitas larva yang diakibatkan oleh ekstrak $50 \mathrm{~g}$ serbuk/l air tanpa deterjen (tanpa direbus dan direbus selama 10, 20, dan 30 menit) masing-masing sebesar 43,33\%, 45\%, $46,68 \%$ dan $46,68 \%$. Fenomena ini mengindikasikan 
adanya dua hal yang cukup penting. Pertama bahwa penambahan deterjen $0,2 \%$ pada erkstrak biji tanaman mindi tidak berpengeruh terhadap kadar bahan aktif yang terlarut dalam ekstrak, atau dengan kata lain penambahan deterjen tidak berpengaruh terhadap keefektifan ekstrak biji tanaman mindi terhadap larva S. litura. Sementara menurut Prijono (1999), penambahan deterjen sebelum perebusan ekstrak merupakan salah satu upaya untuk meningkatkan konsentrasi bahan aktif dalam ekstrak yang diperoleh. Kedua, keefektifan ekstrak biji tanaman mindi terhadap $S$. litura lebih dipengaruhi oleh konsentrasi bahan baku dan lamanya perebusan ekstrak, makin tinggi konsentrasi bahan baku ekstrak disertai dengan perebusan selama 10 - 20 menit akan menghasilkan ekstrak dengan kadar bahan aktif yang lebih tinggi sehingga akan bekerja lebih efektif.

\section{Pengaruh ekstrak biji tanaman mindi terhadap lama perkembangan larva $S$. litura}

Pengaruh ekstrak biji tanaman mindi terhadap lama perkembangan larva $S$. litura dari instar pertama hingga akhir instar ketiga disajikan pada Tabel 1 . Lama perkembangan larva instar pertama sampai akhir instar ketiga setelah diberi perlakuan ekstrak biji tanaman mindi, tidak berbeda nyata dengan lama perkembangan larva pada kontrol, yaitu berkisar antara 10,12 sampai 10,34 hari. Hal ini menunjukkan, bahwa ekstrak biji tanaman mindi tidak memiliki sifat menghambat perkembangan $(\mathrm{IGR}=$ Insect Groth Regulator) terhadap larva S. litura.

Aktivitas biologi ekstrak biji tanaman mindi terhadap larva $S$. litura tampaknya lebih bersifat insektisida daripada menghambat perkembangan. Hal ini sangat berkaitan dengan jenis dan karakteristik bahan aktif yang terkandung dalam ekstrak. Namun, informasi mengenai kandungan bahan aktif ekstrak biji tanaman mindi ( $M$ azedarach) belum dapat ditemui dalam literatur. Sebagai acuan pendekatan, dari hasil penelitian sebelumnya telah diketahui bahwa tanaman famili Meliaceae seperti Azadirachta indica mengandung bahan aktif azadirachtin, selain bersifat insektisida, juga mampu menghambat makan Spodoptera littoralis hingga 99\% pada konsentrasi bahan aktif 1 ppm (Dadang 1999). Selain itu, Xie et al. (1994) melaporkan bahwa ekstrak etanol beberapa bagian tanaman Trichilia sp. (Fam. Meliaceae) mengandung bahan aktif yang termasuk golongan limonoid, pada konsentrasi $0,2 \%$ dalam makanan buatan mampu menghambat perkembangan larva
Peridroma saucia antara $80 \%$ sampai $100 \%$, selain itu dapat menghambat aktivitas makan larva S. eridania.

\section{SIMPULAN}

disimpulkan bahwa :

Berdasarkan hasil percobaan ini dapat

(1). Ekstrak sederhana biji tanaman mindi memiliki aktivitas insektisida terhadap larva S. litura.

(2). Keefektifan ekstrak biji tanaman mindi terhadap S. litura lebih dipengaruhi oleh konsentrasi bahan baku dan lama perebusan ekstrak

(3). Aktivitas insektisida ekstrak sederhana biji mindi (M. azedarach) dengan konsentrasi $50 \mathrm{~g}$ serbuk/l air yang mengandung deterjen $0,2 \%$ dapat ditingkatkan dengan cara merebusnya selama 10 sampai 20 menit.

(4). Penambahan deterjen sebayak 0,2\% pada ekstrak biji mindi tidak berpengaruh nyata terhadap keefektifan ekstrak terhadap larva S. litura.

\section{DAFTAR PUSTAKA}

Chiu, S.(F.) 1985. Recent research finding on Meliaceae and other promising botanical insecticides in China. Z. Pflkrankh. Pflsch. 92: 310-319.

Dadang. 1999. Sumber insektisida alami. Hlm. 8 20, Dalam B.W. Nugroho, Dadang \& D. Prijono (eds.). Bahan Pelatihan Pengembangan dan Pemanfaatan Insektisida Alami, Bogor, 9 - 13 Agustus 1999. Pusat Kajian Pengendalian Hama Terpadu, IPB.

Ewete, F., R.W. Nicol, V. Hengsawad, P. Sukumalanand, C. Satasook, P. Wiriyachitra, M.B. Isman, Y. Kahn, F. Duval, Bir Philogene \& J.T. Arnason. 1996. Insecticidal activity of Aglaia odorata extract and the active principle, rocaglamide to the European corn borer Ostrinia nubilalis Hubn. (Lepidoptera: Pyralidae). J. Appl. Ent. 120: 483-488.

Koul, O., J.S. Shankar, N. Metha, S.C. Taneja, A.K. Tripathi \& K.L. Dhar. 1997. Bioefficacy of crude extracts of Aglaia species (Meliaceae) and some active fractions against lepidopteran larvae. J. Appl. Ent. 121: 245-248. 
Parrella, M.P. \& C.B. Keil. 1984. Insect pest management: the lessons of Liriomyza. Bull. Entomol. Soc. Amer. 30: 22-25

Prijono, D. 1998. Insecticidal activity of meliaceous seed extracts against Crocidolomia binotalis Zeller (Lepidoptera: Pyralidae). Bul. HPT 10: $1-6$.

Prijono, D. 1999. Prinsip-prinsip uji hayati. Hlm. 45 62. Dalam BW Nugroho, Dadang \& D. Prijono (eds.). Bahan Pelatihan Pengembangan dan Pemanfaatan Insektisida Alami, Bogor, 9 - 13 Agustus 1999. Pusat Kajian Pengendalian Hama Terpadu, IPB.

SAS Institute. 1990. SAS User's Guide Version 6. SAS Institute, Raleigh, North Carolina.

Satasook, C., M.B. Isman, F. Ishibasi, S. Medbury, P. Wiriyachitra \& G.H.N. Towers. 1994. Insecticidal bioactivity of crude extracts of Aglaia species (Meliaceae). Biochem. System Ecol. 22: 121-127.
Schmutterer, H. (Ed.). 1995. The neem tree Azadirachta indica A. Juss. and other meliaceous plants: sources of unique natural products for integrated pest management, medicine, industry and other purposes. Weinheim (Germany): VCH.

Soekarna, D. 1984. Ulat Grayak dan Pengendaliannya. Makalah dalam Rapat Komisi Perlindungan Tanaman di Cisarua. Balai Penelitian Tanaman Pangan Bogor. Bogor.

Xie, Y.S., M.B. Isman, P. Gunning, S. MacKinnon, J.T. Arnason, D.R. Taylor, P. Sanchez, C. Hasbun, \& G.H.N. Towers. 1994. Biological activity of extracts of Trichilia spesies and the limonoid hirtin against lepidoptera larvae. Biochem. System Ecol. 22: 129-136. 